\title{
Características laboratoriais das ceratites e conjuntivites causadas por Streptococcus sp
}

\author{
Laboratorial findings of Streptococcus keratitis and conjunctivitis
}

\author{
Helena Parente Solari ${ }^{1}$ \\ Luciene Barbosa de Sousa ${ }^{2}$ \\ Denise de Freitas ${ }^{3}$ \\ Maria Cecília Zorat $\mathbf{Y u}^{4}$ \\ Ana Luisa Höfling'-Lima ${ }^{5}$
}

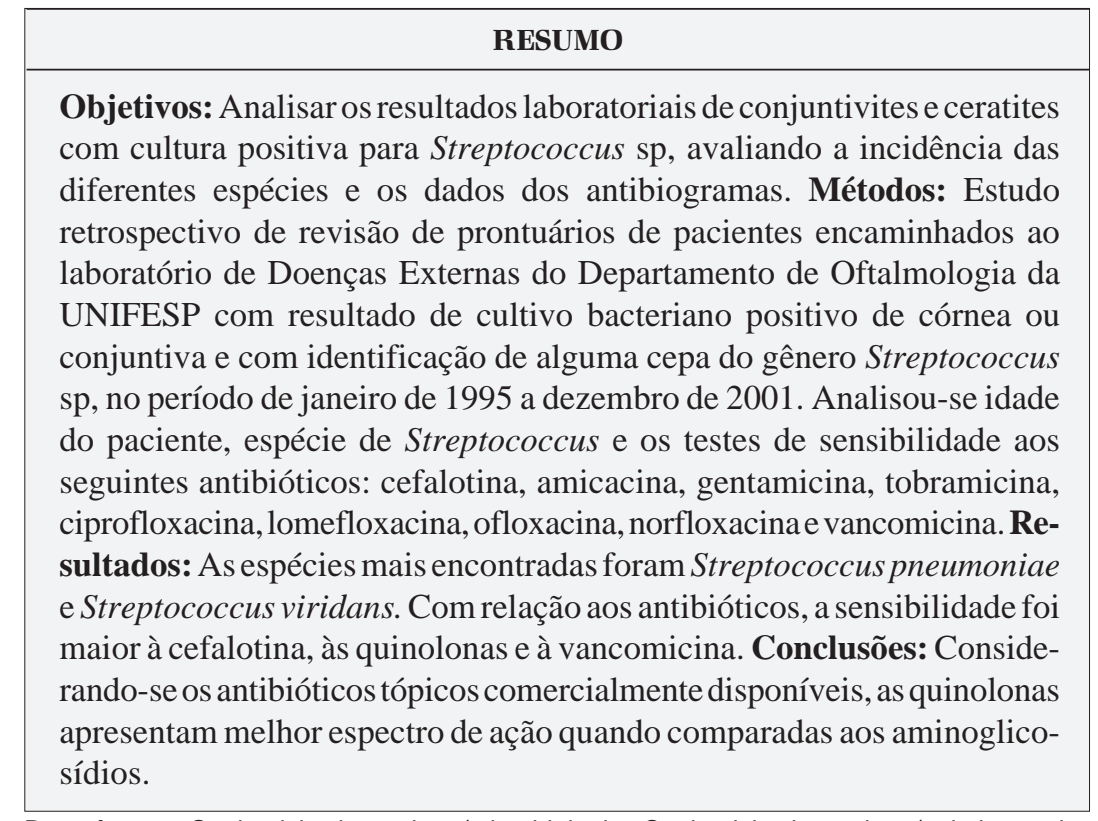

Descritores: Conjuntivite bacteriana/microbiologia; Conjuntivite bacteriana/quimioterapia; Ceratite/microbiologia; Ceratite/quimioterapia; Infecções oculares bacterianas/microbiologia; Streptococcus pneumoniae/isolamento \& purificação; Streptococci viridans/isolamento \& purificação; Fluoroquinolonas/uso terapêutico; Quinolonas/uso terapêutico; Agentes antibacterianos/uso terapêutico
Trabalho realizado na Universidade Federal de São Paulo - UNIFESP

${ }^{1}$ Pós-graduanda do Departamento de Oftalmologia da Universidade Federal de São Paulo - UNIFESP

${ }^{2}$ Chefe do Setor de Córnea e Doenças Externas do Departamento de Oftalmologia da Universidade Federal de São Paulo - UNIFESP

${ }^{3}$ Professora Livre-Docente do Departamento de Oftalmologia da Universidade Federal de São Paulo UNIFESP

${ }^{4}$ Biomédica Responsável pelo Laboratório do Departamento de Oftalmologia da Universidade Federal de São Paulo - UNIFESP

Chefe do Departamento de Oftalmologia da Universidade Federal de São Paulo - UNIFESP

Endereço para correspondência: Helena Parente Solari, Rua Pedro de Toledo 544/600 - São Paulo (SP) CEP 04039-001

E-mail: helenasolari@hotmail.com

Recebido para publicação em 24.10.2003

Versão revisada recebida em 12.04.2004

Aprovação em 22.04.2004

\section{INTRODUÇ̃̃OO}

A superfície ocular é normalmente colonizada por uma microbiota bacteriana. Alterações da microbiota são observadas em várias situações, principalmente devido à diminuição da imunidade local e sistêmica do hospedeiro ou pela presença de microorganismos virulentos. A conjuntivite bacteriana é uma doença ocular comum causada por uma ou mais espécies de bactérias e seu quadro clínico caracteriza-se basicamente por hiperemia conjuntival e secreção purulenta. Como os principais agentes etiológicos das conjuntivites são conhecidos, o tratamento inicial é feito com antibiótico de amplo espectro que tenha boa sensibilidade para cocos Gram positivos ${ }^{(1-2)}$.

As ceratites infecciosas são importantes causas de comprometimento visual, sendo a infecção de etiologia bacteriana a causa mais freqüente de infecção da córnea. Os microorganismos envolvidos em um processo infeccioso ocular podem variar de acordo com a região geográfica e com fatores predisponentes, sendo o quadro clínico peculiar, devendo ser diferenciado de outras condições inflamatórias da córnea ${ }^{(1-3)}$.

A maioria das doenças infecciosas pode ser diagnosticada e tratada 
considerando-se apenas as características clínicas. A investigação laboratorial pode minimizar a morbidade secundária a um diagnóstico etiológico tardio, proporcionar conforto ao paciente e prevenir complicações que comprometam a visão; desta forma está indicada na maioria dos pacientes com suspeita clínica de ceratite infecciosa ${ }^{(1-3)}$.

Considerando-se a alta incidência de infecção ocular por Streptococcus sp, este estudo tem como objetivo avaliar retrospectivamente os resultados laboratoriais de conjuntivites e ceratites com cultura positiva para Streptococcus $\mathrm{sp}$, de pacientes atendidos no Departamento de Oftalmologia da UNIFESP, no período de janeiro de 1995 a dezembro de $2001^{(2-5)}$.

\section{MÉTODOS}

Realizou-se estudo retrospectivo de revisão de prontuários de pacientes encaminhados ao Laboratório de Doenças Externas do Departamento de Oftalmologia da UNIFESP, com resultado de cultivo bacteriano positivo de córnea ou conjuntiva, tendo sido avaliados os casos com identificação de alguma cepa do gênero Streptococcus sp, no período de janeiro de 1995 a dezembro de 2001. As amostras de conjuntiva ou córnea foram cultivadas nos seguintes meios de cultura: ágar sangue, ágar chocolate e ágar Sabouraud. Analisou-se idade do paciente, espécie de Streptococcus e os testes de sensibilidade aos seguintes antibióticos: cefalotina, amicacina, gentamicina, tobramicina, ciprofloxacina, lomefloxacina, ofloxacina, norfloxacina e vancomicina.

\section{RESULTADOS}

De pacientes com conjuntivite, foram obtidas 1.175 amostras com cultivo bacteriano positivo neste período, com Streptococcus sp isolado em 78 amostras $(6,63 \%)$, com média de idade dos pacientes de 17,5 anos. As amostras foram distribuídas de acordo com a espécie em: 3 Streptococcus $\mathrm{sp}(3,84 \%), 28$ Streptococcus pneumoniae (35,89\%), 23 Streptococcus viridans $(29,48 \%), 3$ Streptococcus pyogenes $(3,84 \%)$ e 21 Streptococcus não hemolítico (26,92\%). Foram descritas como Streptococcus $\mathrm{sp}$ as amostras que não tiveram as espécies identificadas.
$\mathrm{Na}$ avaliação dos testes de sensibilidade aos antibióticos, cada grupo de bactérias pertencente à mesma espécie foi analisado separadamente, sendo que das 3 cepas de Streptococcus pyogenes, apenas 2 tiveram o antibiograma realizado (Tabela 1).

Com relação às amostras de córnea obtidas de ceratites, 629 cultivos foram positivos para bactéria e 164 (26,07\%) foram positivos para o gênero Streptococcus, com média de idade dos pacientes igual a 46,5 anos. A distribuição de acordo com a espécie foi: 7 Streptococcus sp (4,26\%), 84 Streptococcus pneumoniae $(51,21 \%), 51$ Streptococcus viridans $(31,09 \%), 3$ Streptococcus pyogenes $(1,82 \%)$ e 19 Streptococcus não hemolítico $(11,58 \%)$. Os resultados observados nos antibiogramas foram descritos separadamente (Tabela 2).

\section{DISCUSSÃO}

Neste levantamento, a prevalência de isolamentos positivos de Streptococcus sp em casos de conjuntivite foi $6,63 \%$, sendo as espécies mais comuns $S$. pneumoniae, $S$. viridans e Streptococcus não hemolítico. No antibiograma das espécies mais freqüentes, observamos uma maior susceptibilidade à cefalotina, às quinolonas e à vancomicina. Em estudo realizado em 1998, 37 amostras de 92 casos de conjuntivite foram positivas para S. pneumoniae, correspondendo a $40,22 \%$ dos $\operatorname{casos}^{(4)}$. Em estudo considerando os 2 principais patógenos de conjuntivite bacteriana em crianças, Haemophilus influenzae e Streptococcus pneumoniae, foram encontrados 75 casos de Streptococcus pneumoniae (30\%), com susceptibilidade maior à ciprofloxacina e ofloxacina, e atividade intermediária de gentamicina e tobramicina. Os autores consideram como melhor opção terapêutica uma fluoroquinolona tópica ${ }^{(5)}$. Em outros estudos, o Staphylococcus aureus e o S. epidermidis, são considerados agentes etiológicos mais comuns ${ }^{(5-6)}$.

A prevalência das ceratites causadas por Streptococcus em nossos dados foi de $26,07 \%$, mas os valores encontrados na literatura variam nos diferentes estudos. Alguns trabalhos incluem Streptococcus sp entre os microorganismos mais isolados em casos de ceratite; enquanto que outros autores relatam uma menor freqüência, variando de $2,5 \%$ a $13,5 \%$ (2,5,7-8) Quanto às espécies, as mais comuns foram Streptococcus

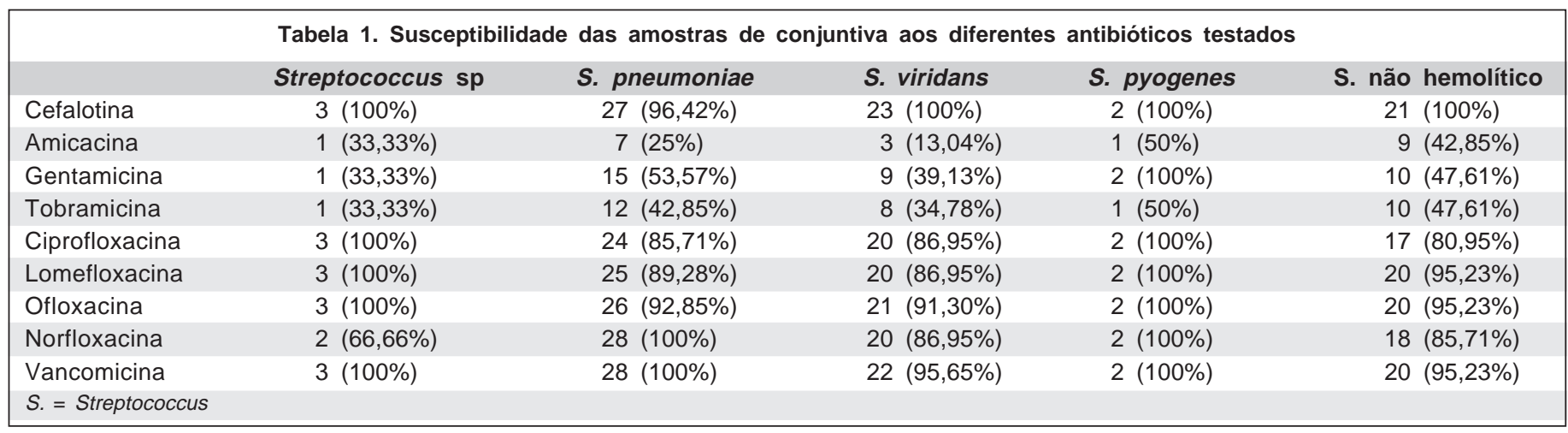




\begin{tabular}{|lccccc|}
\hline & \multicolumn{2}{c}{ Tabela 2. Susceptibilidade das amostras de córnea aos diferentes antibióticos testados } \\
& Streptococcus sp & S. pneumoniae & S. viridans & S. pyogenes & S. não hemolítico \\
Cefalotina & $6(85,71 \%)$ & $84(100 \%)$ & $46(93,87 \%)$ & $3(100 \%)$ & $17(100 \%)$ \\
Amicacina & $7(100 \%)$ & $17(20,23 \%)$ & $49(100 \%)$ & $1(33,33 \%)$ & $14(82,35 \%)$ \\
Gentamicina & $6(85,71 \%)$ & $21(25 \%)$ & $16(32,65 \%)$ & $2(66,66 \%)$ & $16(94,11 \%)$ \\
Tobramicina & $6(85,71 \%)$ & $23(27,38 \%)$ & $14(28,57 \%)$ & $2(66,66 \%)$ & $3(100 \%)$ \\
Ciprofloxacina & $7(100 \%)$ & $79(94,04 \%)$ & $34(69,38 \%)$ & $3(100 \%)$ & $14(82,35 \%)$ \\
Lomefloxacina & $7(100 \%)$ & $74(88,09 \%)$ & $28(57,14 \%)$ & $3(100 \%)$ & $17(100 \%)$ \\
Ofloxacina & $7(100 \%)$ & $73(86,90 \%)$ & $37(75,51 \%)$ & $3(100 \%)$ \\
Norfloxacina & $6(85,71 \%)$ & $73(86,90 \%)$ & $32(65,30 \%)$ & $3(100 \%)$ \\
Vancomicina & $7(100 \%)$ & $84(100 \%)$ & $49(100 \%)$ & $17(100 \%)$ \\
S. = Streptococcus & & & & \\
\hline
\end{tabular}

pneumoniae e viridans, correspondendo a $82,30 \%$ das amostras positivas para Streptococcus sp, resultado similar a outros estudos $^{(7,9)}$.

Com relação à susceptibilidade aos antibióticos, em geral as amostras foram mais sensíveis à cefalotina, às quinolonas e à vancomicina, em concordância com outros relatos ${ }^{(1-2,9-10)}$. Apesar da boa susceptibilidade do Streptococcus às quinolonas em geral, já há descrito na literatura um aumento do número de cepas resistentes, tornando assim, a vancomicina uma boa opção terapêutica ${ }^{(11-14)}$.

O tratamento tradicional das ceratites infecciosas baseiase na coleta de amostras para investigação laboratorial, seguida da instituição de antibióticos fortificados de amplo espectro, geralmente uma cefalosporina associada a um aminoglicosídio, até a definição do diagnóstico etiológico ou melhora clínica, porém os antibióticos fortificados apresentam desvantagens relacionadas à toxicidade, custo, possibilidade de contaminação, necessidade de refrigeração e curta durabilida$\mathrm{de}^{(4,13)}$. Como opção terapêutica, as quinolonas são utilizadas em geral empiricamente como monoterapia, em virtude de seu amplo espectro de ação, além de apresentarem baixa toxicidade, boa penetração na superfície ocular e alta concentração no filme lacrimal ${ }^{(13-15)}$. Observando os dados encontrados em nosso estudo podemos concluir que o tratamento empírico com quinolona seria eficaz em parte dos casos causados por Streptococcus sp, com exceção dos quadros de ceratite causados por $S$. viridans onde notamos baixos níveis de susceptibilidade às quinolonas em geral; considerando-se que este é um agente etiológico freqüente nas úlceras de córnea, a utilização de monoterapia pode não ser eficaz. Dados da literatura também descrevem casos de resistência bacteriana ao tratamento empírico, reforçando, portanto a importância da indicação de pesquisa laboratorial com coleta de amostra para cultura nos casos de infecção ${ }^{(7-8,13)}$.

\section{CONCLUSÕES}

Em nosso estudo, dentre os antibióticos comercializados, as quinolonas são os que apresentam um melhor espectro de ação quando comparado aos aminoglicosídios. Ressalta-se que estes dados são baseados em resultados laboratoriais, de testes de sensibilidade in vitro, a qual nem sempre corresponde à sensibilidade in vivo e sua função terapêtica. No tratamento de infecções, a correlação clínico-laboratorial deve sempre ser realizada para que seja completa a ação de determinado antibiótico.

\section{ABSTRACT}

Purpose: To evaluate laboratorial findings of Streptococcus keratitis and conjunctivitis, analyzing the different species and the results of bacterial susceptibility to an antibiotics. Methods: Retrospective study of the records from the External Disease Laboratory of the Ophthalmology Department of the Federal University of São Paulo, with conjunctival or corneal positive bacterial culture for Streptococcus sp, between January 1995 and December 2001. The collected data were age, Streptococcus species and the bacterial susceptibility to the following antibiotics: cephalotin, amikacin, gentamicin, tobramicin, ciprofloxacin, lomefloxacin, ofloxacin, norfloxacin and vancomicin. Results: The most frequent species were Streptococcus pneumoniae and Streptococcus viridans. Regarding bacterial susceptibility to antibiotics we found a higher susceptibility to the following antibiotics: cephalotin, quinolones and vancomicin. Conclusions: Considering the commercially available topic antibiotics, the quinolones presented better results when compared to the aminoglycosides.

Keywords: Conjunctivitis, bacterial/microbiology; Conjunctivitis, bacterial/drug therapy; Keratitis/microbiology; Keratitis/drug therapy; Eye infections, bacterial/microbiology; Streptococcus pneumoniae/isolation \& purification; Viridans, streptococci/isolation \& purification; Fluoroquinolones/ therapeutic use; Quinolones/therapeutic use; Antibacterial agents/therapeutic use

\section{REFERÊNCIAS}

1. Höfling-Lima AL, Belfort Jr R. Ceratites bacterianas. In: Belfort Jr R, KaraJosé N. Córnea clínica-cirúrgica. São Paulo: Roca; 1996. p.181-8. 
2. Alves MR, de Andrade BBA. Úlcera de córnea bacteriana. Arq Bras Oftalmol. 2000;63(6):495-501.

3. Liesegang TJ. Bacterial keratitis. In: Kaufman HE, Barron BA, McDonald MB. The cornea. Boston: Butterworth-Heinemann; 1997. p.159-218.

4. Schaefer F, Bruttin O, Zografos L, Guex-Crosier Y. Bacterial keratitis: a prospective clinical and microbiological study. Br J Ophthalmol. 2001;85(7): 842-7.

5. Medeiros MIC, Neme SN, da Silva P, Silva JO, Carneiro AMM, Carloni MC, Brandileone MCC. Streptococcus pneumoniae and Haemophilus influenzae as etiological agents of conjunctivitis outbreaks in the region of Ribeirão Preto, SP, Brazil. Rev Inst Med Trop. 1998;40(1):11-6.

6. Block SL, Hedrick J, Tyler RE, Smith A, Findlay R, Keegan E, et al. Increasing bacterial resistance in pediatric acute conjunctivitis (1997-1998). Antimicrob Agents Chemoter. 2000;44(6):1650-4.

7. Honig MA, Cohen EJ, Rapuano CJ, Laibson PR. Corneal ulcers and the use of topical fluoroquinolones. CLAO J. 1999;25(4):200-3.

8. Graves A, Henry M, O'Brien TP, Hwang DG, Buskirk AV, Trousdale MD. In vitro susceptibility of bacterial ocular isolates to fluoroquinolones. Cornea 2001;20(3):301-5. Erratum in: Cornea. 2001;20(5);546.
9. Höfling-Lima AL, Moeller CTA, Yu MCZ, Branco BC, Farah ME. Microbiological efficacy of lomefloxacin and other drugs regarding microorganisms isolated from the human conjunctiva. Arq Bras Oftalmol. 2001;64(2): $147-51$

10. Uesugui E, Cypel-Gomes MC, Atique D, Goulart DG, Galluci FR, Nishiwaki-Dantas MC, et al. Identificação laboratorial dos patógenos oculares mais freqüentes e sua susceptibilidade in vitro aos agentes antimicrobianos. Arq Bras Oftalmol. 2002;65(3):339-42.

11. Knauf HP, Silvany R, Southern PM, Risser RC, Wilson SE. Susceptibility of corneal and conjunctival pathogens to ciprofloxacin. Cornea. 1996;15(1): 66-70.

12. Kowalski RP, Karenchak LM, Gordon YJ. Comparison of ciprofloxacin and ofloxacina using human corneal susceptibility levels. Cornea. 1998;17(3):282-7.

13. Goldstein MH, Kowalski RP, Gordon YJ. Emerging fluoroquinolone resistance in bacterial keratitis. A 5-year review. Ophthalmology. 1999;106(7):1313-8.

14. Kowalski RP, Romanowski EG, Yates KA, Gordon YJ. Lomefloxacin is an effective treatment of experimental bacterial keratitis. Córnea. 2001;20(3):306-8.

15. Smith A, Pennefather PM, Kaye SB, Hart CA. Fluoroquinolones. Place in ocular therapy. Drugs. 2001;61(6):747-61.

\section{SIMPÓSIO INTERNACIONAL DA SANTA CASA dE SÃo PAULO}

\section{CONGRESSO BRASILEIRO DE ESTRABISMO E OfTALMOlogia pediátrica}

\section{O९ a 11 de Junho de 2005} Sc̃॰ Paul॰ - SP

INFORMAC̣ÕES: JDE Comunicação e Eventos

Tels: (11) 5084-5284 / 5082-3030

Fax: (11) 5574-8261

E-mail: jdecomev@uol.com.br

Home-page: jdeeventos.com.br 